\title{
A Proposal for the Evaluation of Final Year Projects in a Competence-based Learning Framework
}

\author{
Rubén Fraile, Irina Argüelles, Juan C. González, Juana M. Gutiérrez-Arriola, César Benavente, \\ Luis Arriero and David Osés \\ Escuela Universitaria de Ingeniería Técnica de Telecomunicación, \\ Universidad Politécnica de Madrid \\ Madrid, Spain \\ E-mail: \{rfraile | irina |jcgsande |jmga | cbpeces | larriero | doses \} a)euitt.upm.es
}

\begin{abstract}
The authors propose a system for the assessment of Final Year Projects (FYPs) whose educational outputs have been defined previously in terms of competences. For building the proposal, eleven pre-defined competences were ranked and a different weight was assigned to each one. The ranking was made individually by all the authors following a blind two-step process. The first step consisted in ordering the competences by relevance and the second step in grading that relevance for each pair of competences having consecutive positions in the list. As a result, an overall weight was computed for each competence and the final proposal was produced by averaging the individual proposals. In addition, three moments are defined for the assessment of FYPs: the FYP process itself, the written report and the oral presentation. Bearing in mind this, the competences that can be evaluated in each moment are identified and a specific assessment form for each moment is also proposed.
\end{abstract}

Keywords-component; engineering education, student assessment, competence-based learning, final year projects

\section{INTRODUCTION}

Project-based learning (PBL) has been recognized for long as a very valuable tool for engineering courses, since it helps students in developing skills that are closely linked to the execution of professional engineering tasks [1]. The recognition of this value of $\mathrm{PBL}$ has lead to the inclusion of project development activities in engineering courses [2], being the "Final Year Project" (FYP) the most remarkable of these.

In the currently ongoing process of creating the European Higher Education Area [3], the educational outcomes of university courses are being defined in terms of competences that are to be acquired by the students in order to get their degrees. Significantly, competences related to project management and development seem to be becoming relevant even for non-engineering courses [4]. In this context, both a definition of the pedagogical content of FYPs in terms of competences and a systematic assessment system linked to those competences are needed.

The issue of defining the educational outcomes of FYPs was approached by the authors in a previous work [5]. Within that work a set of eleven competences relevant for FYPs were identified, using the basis provided by [4] and [6]. Also in [5],

The work reported in this paper has been carried out in the framework of a Project for Educational Innovation funded by the Universidad Politécnica de Madrid competences were broken down into specific learning objectives and student tasks to be realized during the FYP were pointed out.

However, in authors' view, the question of defining a systematic approach to the evaluation of FYPs has not been satisfactorily solved so far. While it is true that the problem of assessing student projects is not new and that rubrics are becoming a standard for such assessment [7], the definition of rubrics for all the assessable aspects of FYPs is cumbersome. Moreover, filling such rubrics could be too time-consuming for the juries of the projects and an excessive level of detail could also mislead the attention of the juries towards too specific aspects of the work, thus making them lose the global view [8].

Another aspect of the evaluation of FYPs that is not defined yet, to authors' knowledge, is the ranking of competences, that is, the specification of which aspects should contribute the most to the final marks assigned to the students. Although a weighted average of different aspects was proposed in [9], such proposal did not consider competence-based learning; therefore it is not coherent with the current trends in the design of university courses in Europe.

Within this paper, the authors propose a system for the assessment of FYPs whose educational outputs have been defined accordingly to [5]. For making the proposal, the eleven selected competences were ranked and a different weight was assigned to each one. Also starting from the work in [5], but simplifying the therein described proposal, three moments are defined for the assessment of FYPs: the FYP development process itself (evaluated by the supervisor), the written report and the oral presentation (both evaluated by a jury). Bearing in mind this, the competences that can be evaluated in each moment have been identified and a specific assessment form for each moment is also proposed within the paper. In the design of the forms, both the simplicity and the prevalence of global aspects have been pursued.

\section{EDUCATIONAL OUTCOMES}

The definition of the educational objectives of FYPs in [5] was done by relating the experience of the authors in FYP supervision to a selected set of competences drawn from [4] and [6]. Within that approach, learning outcomes were 
structured in four levels of abstraction: classes of competences, competences, learning objectives and project achievements. While this structure provided a comprehensive means to relate project activities to learning outcomes expressed in terms of competences, it was too detailed to be manageable both by students and lecturers as a guidance for the learning process associated to FYPs. Consequently, herein only the two levels with the highest degree of abstraction have been considered for the formal definition of learning outcomes: classes of competences and competences, as specified next.

\section{A. Classes of competences}

The educational purposes of the FYP can be classified, at the most general level, in four types or classes of competences:

1) Intellectual competences: related to the way reality is analyzed, reasoning on it is produced and proposals to change it are generated.

2) Instrumental competences: related to knowledge, techniques and working procedures that must have been acquired prior to the beginning of the FYP.

3) Managerial competences: related to the planning and implementation of activities, be them either individual or in group.

4) Social contextualization competences: related to analyzing and previewing the interaction between technology and the social context in which it takes place.

\section{B. Competences}

Individual competences that must be improved during the development of the FYP have been identified within each group.

\section{1) Intellectual competences}

C-I. Competence for analyzing and synthesizing: capacity for compiling, comprehending, interpreting and evaluating information and data relative to a technological problem in such a way that its main aspects can be easily identified.

C-II. Competence for applying knowledge to practice: capacity for solving specific problems making use of the specialized knowledge of the correspondent technology and for conceiving, if needed, new systems or devices that help in achieving the objectives and requirements of the undertaken problem.

C-III. Competence for making research: capacity for generating new knowledge from hypothesis and data, making use of the scientific method.

C-IV. Competence for scientific and rational analysis: attitude for systematically analyzing reality from a rationalscientific point of view, which is characterized by the appropriate use of theories and models, the production of coherent interpretations of facts, the critical analysis and the forming of personal opinions and judgments.
2) Instrumental competences

$\mathrm{C}-\mathrm{V}$. Competence for dealing with the basic knowledge of the technological area: familiarity with the basic concepts of the correspondent knowledge and technological area and capacity to increase the personal knowledge through autonomous study

C-VI. Competence for managing information: capacity for finding information in bibliographies, distinguishing between primary and secondary bibliographic sources, making good use of libraries and locating information on the World Wide Web while assessing its reliability.

C-VII. Competence for performing basic tasks with computers: capacity for creating and storing information in several formats, for complying with norms relative to those formats, for communicating making use of computer networking, for using on-line resources, for registering experimental data in electronic format and for using software specific to the correspondent knowledge area.

C-VIII. Competence for language communication: capacity for elaborating written texts and oral dissertations following orthographic and grammatical rules, with a coherent ordering of ideas and arguments and with different levels of detail; having good fluency in a second language, at least in reading comprehension.

3) Managerial competences

C-IX. Competence for inter-personal relations: capacity for listening others' opinions and views, for using verbal and non-verbal codes, for working in a team and, if necessary, leading it, for presenting proposals and projects, for debating, for conducting interviews, for generating interactive environments, for interacting with people coming from diverse social and cultural contexts.

C-X. Competence for task managing: capacity for organizing time, for setting priorities, for working under pressure, for complying with compromises in results and time.

4) Social contextualization competence

$\mathrm{C}$-XI. Competence for analyzing the social context: consciousness of the existence and the origin of social conditions, restrictions, beliefs and usages and capacity for assessing the social and ethical impact of technological projects.

As stated before, the educational purposes of the FYP could be further concretized. However, in the authors' view, this level is enough both to inform students on what they are expected to do and to design a competence-based FYP assessment system, as proposed in next section.

\section{EVALUATION}

\section{A. Assessment procedure}

As stated in section I, the student evaluation in a competence-based learning paradigm should be competencebased too [8]. Therefore, the herein proposed procedure for FYP assessment consists in directly evaluating up to which level the student has acquired each of the 11 competences 
involved in FYPs. In this way, the students' attention is not deviated towards specific aspects whose artificially increased relevance could bias the overall educational aim and, at the same time, the coherence between FYP educational objectives and assessment process is kept.

However, the diversity of competences to be evaluated results in a corresponding diversity of evaluation times and people involved. Considering both common practice and the FYP achievements listed in [5], at least three evaluation moments and agents can be identified:

- Implementation process: the work of each student can be assessed continuously by the FYP supervisor during group and individual meetings and also considering the project plan and the cooperation with other students.

- Final report: evaluated by a board formed by lecturers.

- Oral presentation: also evaluated by a board of lecturers with possible inclusion of colleague students.

Table I summarizes the authors' view on which competences can be evaluated in each of the three abovementioned moments. A detailed justification for this relation between competences and moments can be found in [5]. From this table, it becomes clear that the three evaluation moments are complementary in the sense that none of them can account for all the competences. Moreover, according to the same table, the evaluation board needs at least two of these views of the project to have a complete overview of it. Tables II, III and IV contain the questionnaires proposed for the evaluation at each of the three moments.

Regarding the issue of how to combine the marks given in all moments to produce a final mark for each competence, a variety of possible procedures exists, but the authors propose a consensus among the evaluators built in a private meeting after the oral presentation.
TABLE I.

COMPETENCES AND EVALUATION MOMENTS

\begin{tabular}{|l|c|c|c|}
\hline \multicolumn{1}{|c|}{ Competence } & 宝 & 宅 & X \\
\hline C-I Analyzing and synthesizing & $\mathrm{X}$ & $\mathrm{X}$ & \\
\hline C-II Applying knowledge to practice & $\mathrm{X}$ & $\mathrm{X}$ & \\
\hline C-III Making research & $\mathrm{X}$ & $\mathrm{X}$ & \\
\hline C-IV Scientific and rational analysis & $\mathrm{X}$ & $\mathrm{X}$ & $\mathrm{X}$ \\
\hline C-V ... knowledge of the technological area & $\mathrm{X}$ & $\mathrm{X}$ & $\mathrm{X}$ \\
\hline C-VI Managing information & $\mathrm{X}$ & $\mathrm{X}$ & \\
\hline C-VII Performing basic tasks with computers & $\mathrm{X}$ & $\mathrm{X}$ & $\mathrm{X}$ \\
\hline C-VIII Language Communications & & $\mathrm{X}$ & $\mathrm{X}$ \\
\hline C-IX Inter-personal relations & $\mathrm{X}$ & & $\mathrm{X}$ \\
\hline C-X Task managing & $\mathrm{X}$ & & \\
\hline C-XI Analyzing the social context & $\mathrm{X}$ & $\mathrm{X}$ & $\mathrm{X}$ \\
\hline
\end{tabular}

\section{B. Competence ranking and weighting}

A second question that arises in the design of the evaluation process when a final numeric mark has to be assigned to the FYP of a student is how to rank the competences and how to weight the marks given to each one in order to obtain a global mark. For solving this question, the authors have followed a two-stage procedure inspired by [10]:

- As a first step, each author has ordered the 11 competences by their relevance for FYPs.

- Secondly, a weight has been assigned to each competence relative to the following one in the ordered list. After that, a simple set of linear equations has allowed to convert these weights to a set summing $100 \%$.

TABLE II. QUESTIONNAIRE FOR THE EVALUATION OF THE ORAL PRESENTATION

\begin{tabular}{|l|l|l}
\hline Competence & Mark \\
\hline
\end{tabular}

C-IV Scientific and rational analysis: The student has presented his or her work in a well structured way. He or she has adequately justified his or her decisions, proposals and answers.

C-V ... knowledge of the technological area: The student has shown good knowledge of the subject in which the project is framed. He or she has used specific vocabulary properly and avoided superficial analyses.

C-VII Performing basic tasks with computers: The student has adequately used supporting software for the presentation, shown well elaborated graphs and, if needed, performed software demonstrations.

C-VIII Language communication: The structure of the presentation has been appropriate. Repetitions and ambiguities have been avoided. The language has been clear and concise and using appropriate vocabulary and register. The presentation length has been adapted to its contents.

C-IX Inter-personal relations: The student has succeeded in maintaining the attention of the audience. He or she has answered all questions without avoiding any and recognized own mistakes. His or her position in the room and speech loudness and speed have also been appropriate. Reading has been avoided.

C-XI Analyzing the social context: The student has spoken about the social context and relevance of the work. Topics and superficial approaches in analyzing ethical issues have been avoided. He or she has shown sensitivity towards the social impact of the project. 
Competence

C-I Analyzing and synthesizing: The student has understood the proposed problem and all its conditions and circumstances. He or she has been autonomous in critically searching, gathering and processing information. He or she has succeeded in relating the problem to others previously approached.

C-II Applying knowledge to practice: The student has been autonomous in applying scientific knowledge and he or she has proposed well founded hypothesis and methods. Changes in methods and objectives have been well reasoned.

Required time and equipment resources have been defined beforehand.

C-III Making research: The student has shown ability to approach problems at different levels of abstraction, to design experiments, to process data using appropriate statistical and mathematical tools, to handle specific instrumentation and to interpret results.

C-IV Scientific and rational analysis: The student has identified all the different parts of the problem. He or she has presented and defended arguments in discussions with the supervisor and with other students. He or she has decided based on objective criteria and has used multidisciplinary knowledge when needed.

C-V ... knowledge of the technological area: The student has shown to be competent in dealing with procedures and concepts of his or her knowledge area and also in handling specific instrumentation. He or she has been autonomous in looking for information that helped in solving his or her doubts.

C-VI Managing information: The student has been autonomous in gathering and selecting information. He or she has resorted to several sources of information and has been able to assess the reliability of each one. He or she has made use of on-line resources provided by the university.

C-VII Performing basic tasks with computers: The student is skilled in managing diverse data and document formats, he or she has usually accessed to network resources and services and has appropriately used data processing software and also software specific to his or her knowledge area.

C-IX Inter-personal relations: The student has regularly attended to meetings with the supervisor and has been able both to discuss and defend his or her approaches and to rectify them when needed. He or she has shared ideas with colleagues and, if required, he or she has participated in joint projects and coordinated part of the work.

C-X Task managing: The student has written a project plan, kept a log book of the project activities, respected foreseen deadlines and activities and adjusted the plan when needed.

C-XI Analyzing the social context: The student has evaluated results bearing in mind their applicability. He or she has included ethical and social issues in the context analysis.

These two steps have been taken independently by each author, without knowing the proposals of the rest. Averaging the resulting weights results in the list of relative relevancies of competences included in table $\mathrm{V}$.

Beyond the specific results shown in this list, which obviously are prone to variations depending on the specific group of people involved in its elaboration, the following aspects can be highlighted:

- All authors except for one agree that competences C-II and $\mathrm{C}-\mathrm{V}$ are among the four most relevant.

- All authors except for one agree that competence C-VIII has a medium relevance.

- All authors except for one agree that competence C-III is among the four least relevant.
- All authors agree that competence C-XI is among the three least relevant.

Regarding all this analysis, it should be recalled that the issue being studied here is the relevance of each competence in the educational contents and assessment process of FYPs in an engineering course, not the importance of each competence either in professional life or in other contexts. For instance, being competent in performing tasks with computers is undoubtedly very relevant for engineers, but such competence should be developed mainly before reaching the FYP. Therefore, C-VII plays a minor role in the marking of the FYP. Conversely, while certain research tasks can be developed during the FYP, the competence for making research is more closely related to higher educational levels (eg. doctorate). Again, this is the reason why $\mathrm{C}$-III appears among the least relevant competences. 


\begin{tabular}{|c|c|}
\hline Competence & Mark \\
\hline $\begin{array}{l}\text { C-I Analyzing and synthesizing: Problem description and analysis are based on a sufficiently wide up-to-date } \\
\text { specialized bibliography. The literature review has clearly synthesized contents, it is well structured and it includes a } \\
\text { judicious analysis of the bibliography while avoiding plagiarism. The hypothesis and/or design criteria are clearly linked } \\
\text { to the review of the state of the art. Data collected during the project have been adequately organized and analyzed and } \\
\text { they provide a clear foundation for the conclusions. }\end{array}$ & \\
\hline $\begin{array}{l}\text { C-II Applying knowledge to practice: Project hypothesis and objectives are clearly stated, well founded on theoretical } \\
\text { knowledge and realistic. Project objectives are original and result from a personal contribution of the student. The } \\
\text { proposed methodology is coherent with the objectives, it is clearly explained and justified and it leads to the reported } \\
\text { results. }\end{array}$ & \\
\hline $\begin{array}{l}\text { C-III Making research: Unsolved issues have been identified and corresponding hypothesis have been stated. } \\
\text { Experiments and results have been adequately carried out and collected in order to confirm or reject such hypothesis. Data } \\
\text { analysis has been unbiased and it clearly supports the conclusions. Findings and conclusions have been discussed and } \\
\text { contrasted to previous results present in literature. }\end{array}$ & \\
\hline $\begin{array}{l}\text { C-IV Scientific and rational analysis: The contents of the final a report are well organized. The approach to the project } \\
\text { is systematic. Statements and interpretations are correctly reasoned or founded in adequate bibliography. }\end{array}$ & \\
\hline $\begin{array}{l}\text { C-V ... knowledge of the technological area: Project implementation has involved knowledge related to the university } \\
\text { course, and part of it has required autonomous study by the student. Conceptual errors have been avoided and, if needed, } \\
\text { specific instrumentation has been correctly used and its specifications and using requirements have been reported. }\end{array}$ & \\
\hline $\begin{array}{l}\text { C-VI Managing information: The final report includes a list of references. All references have been cited in the text. } \\
\text { Reference format is as specified. Sources of all copied material have been cited. }\end{array}$ & \\
\hline $\begin{array}{l}\text { C-VII Performing basic tasks with computers: The format specifications of the document have been respected. Usage } \\
\text { of styles and formats is coherent throughout the whole document. Appropriate software has been used for generation of } \\
\text { graphics and data processing. }\end{array}$ & \\
\hline $\begin{array}{l}\text { C-VIII Language communication: The structure of the report is correct. Headings and content are coherent. Both } \\
\text { repetitions and ambiguities are avoided. The text is clear and concise. The length of the final report is adequate for its } \\
\text { contents and it does not contain either syntactic, orthographic or semantic errors. The bibliography is multilingual. }\end{array}$ & \\
\hline $\begin{array}{l}\text { C-XI Analyzing the social context: The project context is mentioned and described. Both practical and ethical } \\
\text { consequences of the project have been considered. }\end{array}$ & \\
\hline
\end{tabular}

TABLE V. RELATIVE RELEVANCE OF COMPETENCES

\begin{tabular}{|c|l|c|}
\hline Rank & Competence & Weight \\
\hline $1^{\text {st }}$ & $\begin{array}{l}\text { C-V Dealing with the basic knowledge of the } \\
\text { technological area }\end{array}$ & $15 \%$ \\
\hline $2^{\text {nd }}$ & C-II Applying knowledge to practice & $14 \%$ \\
\hline $3^{\text {rd }}$ & C-I Analyzing and synthesizing & $13 \%$ \\
\hline $4^{\text {th }}$ & C-VI Managing information & $11 \%$ \\
\hline $5^{\text {th }}$ & C-X Task managing & $9 \%$ \\
\hline $6^{\text {th }}$ & C-IV Scientific and rational analysis & $9 \%$ \\
\hline $7^{\text {th }}$ & C-VIII Language communication & $8 \%$ \\
\hline $8^{\text {th }}$ & C-IX Inter-personal relations & $7 \%$ \\
\hline $9^{\text {th }}$ & C-VII Performing basic tasks with computers & $6 \%$ \\
\hline $10^{\text {th }}$ & C-III Making research & $4 \%$ \\
\hline $11^{\text {th }}$ & C-XI Analyzing the social context & $4 \%$ \\
\hline
\end{tabular}

\section{DISCUSSION}

Within this paper, the authors have presented an overview of an evaluation proposal for FYPs in engineering university studies. While the details of the proposal may be somewhat biased by the professional background of the authors (6 engineers, 1 physicist and 1 linguist, all giving lectures in a telecommunications engineering faculty) and the specifics of their institution, the approach can be easily transferred to other contexts, as reasoned in the next paragraphs.

The assessment procedure is closely related to the educational objectives of the FYP by means of the so called project achievements enumerated in [5]. The proposed procedure follows the rule of directly assessing the relevant educational outcomes, namely the competences, as suggested in [8]. These two criteria, together with the search for simple questionnaires that can be contained within a single sheet of paper, have served as a basis for the proposal. As for the assignment of marks to each competence, although the proposal allows certain degree of subjectivity, it could be complemented with a rubric-type guide for evaluation. It should also be noted that, intentionally, no pre-defined scale for the marks has been given. In the authors' view, this is not a critical aspect of the proposal and it can be adapted to specific circumstances. Still, if an objective orientation were to be given, a scale consisting of four to five levels seems to be appropriate, according to [7] and [11]. 
Regarding the ranking and weighting of competences, the ordered list presented in section III-B is undoubtedly a result of the personal views of the authors. Yet, some aspects of the proposal can be generalized. In the first place, the two-stage approach (ranking in the first place, weighting in the second place) derived as a simplification of the proposal in [10] can be adopted within any group to identify the most and least relevant competences. In the second place, it is also significant that, after an independent ranking-and-weighting process, there was a remarkable degree of agreement in that:

- the knowledge of the technological area and the capacity of applying theory to practice are the most relevant competences to be developed and assessed during the FYP,

- making research and analyzing the social context are among the least relevant and

- the relevance of language communication should not be diminished.

Last, the whole approach could easily be extended to the final works in higher educational levels (e.g. MSc or PhD). As considered in [6], the set of competences to be developed at graduate and postgraduate levels is mainly the same, though the particularization of those competences for each educational level should result in different educational objectives. Thus, the evaluation process could remain basically unchanged but with different weights assigned to each competence, since the purpose of postgraduate studies is not the same as that of undergraduate courses.

\section{REFERENCES}

[1] K. McDermott, A. Nafalski and O. Gol, "Project-based teaching in engineering programs," in 37th Annu. Frontiers in Educ. Conf. - Global Eng.: Knowledge Without Borders, Opportunities Without Passports, Oct. 2007, pp. S1D-11-S1D-17.

[2] J. Jawitz, S. Shay and R. Moore, "Management and assessment of final year projects in engineering," Int. J. of Eng. Educ., vol. 18, no. 4, pp. 472-478, 2002.

[3] European Ministers of Educ., "The European higher education area," European Union, Bologna (Italy), Joint Declaration, 1999. [Online]. Available: $\quad \mathrm{http}: /$ www.ond.vlaanderen.be/hogeronderwijs/bologna/ documents/MDC/BOLOGNA DECLARATION1.pdf

[4] J. Gonzalez and R. Wagenaar, Eds., Tuning educational structures in Europe. Universities' contribution to the Bologna process, 2nd ed. Universidad de Deusto, 2008. [Online]. Available: http://www.tuning.unideusto. org/tuningeu/index.php

[5] R. Fraile et al. "Definition of the educational outcomes of final year projects," in Int. Technology, Educ. and Development Conf. (INTED), Valencia (Spain), Mar. 2009.

[6] A. Meijers, C. van Overveld and J. Perrenet, Criteria for Academic Bachelor's and Master's Curricula, Delft University of Technology, Eindhoven University of Technology and University of Twente, 2005. [Online]. Available: http://w3.ieis.tue.nl/uploads/media/AC ENG web.pdf

[7] T. Markham, J. Larmer, and J. Ravitz, Project-based learning handbook, 2nd ed. Buck Institute for Educ., 2003.

[8] T. Bers, "Measuring and reporting competencies," New Directions for Institutional Research, no. 110, pp. 29-40, 2001

[9] C. Teo and D. Ho, "A systematic approach to the implementation of final year project in an electrical engineering undergraduate course," IEEE Trans. Educ., vol. 41, no. 1, pp. 25-30, 1998.

[10] H. Taira, Y. Fan, K. Yoshiya, and H. Miyagi, "A method of constructing pairwise comparison matrix in decision making," in IEEE Int. Conf. on Systems, Man, and Cybernetics, vol. 4, Oct. 1996, pp. 2511-2516.

[11] "Rubistar. create rubrics for your project-based learning activities," University of Kansas, Sept.2 2009. [Online]. Available: http://rubistar.4teachers.org 